\title{
Investigation of hydrological variability in the Korean Peninsula with the ENSO teleconnections
}

\author{
Sunkwon Yoon ${ }^{1}$ and Taesam Lee ${ }^{2}$ \\ ${ }^{1}$ Climate Application Department, APEC Climate Center, Busan, 48058, Republic of Korea \\ ${ }^{2}$ Department of Civil Engineering, ERI, Gyeongsang National University, 52828, Republic of Korea \\ Correspondence to: Sunkwon Yoon (skyoon@apcc21.org) \\ Published: 17 October 2016
}

\begin{abstract}
This study analyzes nonlinear behavior links with atmospheric teleconnections between hydrologic variables and climate indices using statistical models during warm season (June to September) over the Korean Peninsula (KP). The ocean-related major climate factor, which is the El Niño-Southern Oscillation (ENSO) was used to analyze the atmospheric teleconnections by principal component analysis (PCA) and a singular spectrum analysis (SSA). The nonlinear lag time correlations between climate indices and hydrologic variables are calculated by Mutual Information (MI) technique. The nonlinear correlation coefficients (CCs) by MI were higher than linear CCs, and ENSO shows a few months of lag time correlation. The warm season hydrologic variables in KP shows a significant increasing tendency during the warm pool (WP), and the cold tongue (CT) El Niño decaying years shows a significant decreasing tendency, while the La Niña year shows slightly above normal conditions, respectively. A better understanding of the relationship between climate indices and streamflow, and their local impacts can help to prepare for the river discharge management by water managers and scientists. Furthermore, these results provide useful data for policy makers and end-users to support long-range water resources prediction and water-related policy.
\end{abstract}

\section{Introduction}

The changing of global climate characteristics has induced more frequent extreme climate events, which are closely related to the seasonal variations of regional water resource variabilities (Wang et al., 2000; Pizarro and Lall, 2002; Yoon, 2015). Many climate scientists believe that extreme climate characteristics have changed with the increase in the Earth's temperature, and the frequency of occurrence and intensity of extreme climactic events is expected to gradually increase (IPCC, 2007). In particular, seasonal variations of hydrometeorological variables are closely related to the characteristic changes in the global climate. For the efficient management and prediction of water resources, it is necessary to investigate the relationship between climate factors and hydrological indicators (Kim et al., 2012; Yoon et al., 2013).

The effect of local hydro-meteorological long-term changes do not occur independently and their correlations appear to be based on large-scale circulation pattern changes. It can be predicted a teleconnection based abnormal sea sur- face temperature (SST), and its nonlinear climate systems behavior in ocean-related climate indices such as the El NiñoSouthern Oscillation (ENSO) in the Tropical Pacific Ocean (TPO) region (Piechota and Dracup, 1996; Piechota et al., 1998; Klein et al., 1999). Based on many studies on ENSO, which is major sources of atmospheric large-scale environmental changes, it is well known that they are closely correlated to seasonal variations of local hydrological pattern changes such as precipitation and streamflow (McPhaden et al., 2006).

The different phases of ENSO, which manifests as abnormally warm SST conditions in the central Pacific Ocean region, and its physical mechanism have been actively examined by the TPO coastal region countries scientists. These phases have been called El Niño Modoki, Central Pacific (CP) El Niño, and warm-pool (WP) El Niño etc. Several studies have shown this abnormal SST conditions will occur more frequently due to current conditions of global warming and changing climate. As a representative study, Feng 
et al. (2010) revealed that the El Niño Modoki phenomenon is affecting areas across of the world through significant changes of the large-scale climate and hydrological circulation patterns. The conventional climate indices Niño3 and Niño4 in the TPO region were used to identify the two types of ENSO (Ashok and Yamagata, 2009; Kug et al., 2009; Yeh et al., 2009). However, Ren and Jin (2011) argued for a distinction in the different types of El Niño, cold-tongue (CT) El Niño and WP El Niño, by using the Niño3 and Niño4 SST observation data.

In this study, we analyzed the influence of the long-term hydro-meteorological variability over the East Asia (EA) and the Korean Peninsula (KP) by looking at the conventional strong CT El Niño, different types of WP El Niño, and strong La Niña events as defined by Ren and Jin (2011). Specifically, this study had three main objectives: (1) To analyze the significant large-scale pattern changes and long-term hydrological variability in KP region by the ocean-related abnormal climate phenomenon in accordance with the ENSO; (2) to investigate linkages of the atmospheric teleconnections using a statistical correlation analysis between climatic indices and hydro-meteorological variables over KP; (3) to perform a diagnostic study on the possibility of seasonal prediction for water resources management using climate indices.

\section{Stud basin and data used}

\subsection{Study basin}

The five major river basins (Han River basin, Nakdong River basin, Geum River basin, Seomjin River basin, and Youngsan River basin) and their sub-watersheds are located in the Korean peninsula $\left(126^{\circ} 24^{\prime}-129^{\circ} 02^{\prime} \mathrm{E}, 36^{\circ} 30^{\prime}-38^{\circ} 55^{\prime} \mathrm{N}\right)$. Most of the eastern part of the KP is composed of mountains and valleys with steep slopes, and the western part of the KP is composed of wide plains. $70 \%$ of the annual rainfall occurs during the summer season (June-September) and is characterized by localized rain resulting primarily from tropical cyclones and heavy rainfall during the rainy season. In 2013 survey dataset from the Korean government's Water Resources Management Information System (WAMIS) for the five major river basins showed a total flooded area of about 1.86 million ha and the total flood damage at over 1,673 million with steady increases in the damage scale and loss with every new flood season.

\subsection{Data used}

ENSO data used in this research was obtained from the National Oceanic and Atmospheric Administration (NOAA), which provides monthly ENSO data from the four sites (Niño1+2, Niño3, Niño3.4, and Niño4). Among these sites, observation data from Niño3 $\left(5^{\circ} \mathrm{S}-5^{\circ} \mathrm{N}, 150-90^{\circ} \mathrm{W}\right)$ and Niño4 $\left(5^{\circ} \mathrm{S}-5^{\circ} \mathrm{N}, 160^{\circ} \mathrm{E}-150^{\circ} \mathrm{W}\right)$ sites are known to have strong correlation with El Niño (Trenberth, 1997). The area- averaged sea surface temperature (SST) anomaly over this region is a well-known ENSO index. SST data provided by Hadley Centre, called HadISST, was used to investigate the correlation between a number of hydrologic parameters for each sub-basin and large-scale atmospheric circulation patterns. This dataset has a spatial resolution of $1^{\circ} \times 1^{\circ}$ and is revised monthly (Rayner et al., 2003).

The 1966 to 2012 precipitation and streamflow data was obtained from WAMIS in Korea. The average precipitation was calculated by the Thiessen polygon network method from the 125 precipitation gauge stations in the five major river basins of the KP. The streamflow data was calculated using the Precipitation-Runoff Modeling System (PRMS), a widely applied semi-distributed long-term runoff simulation model developed by the US Geological Survey (Leavesley et al., 1983; Dressler et al., 2006). By using PRMS to calculate the natural streamflow, the effect of artificial dams was eliminated from the streamflow data.

\section{Methodology}

\subsection{Teleconnections}

ENSO phenomenon in the TPO region induced large-scale atmospheric climate pattern changes. To understand their local hydro-environmental impacts in the $\mathrm{KP}$, it is necessary to analyze the linear and non-linear correlations and its lag time correlations between climate indices and hydrometeorological variables. In general, abnormal SST in the TPO region has triggering effects for the troposphere temperature rise. A teleconnection, enabled by the jet stream, connects the abnormal SST variation in these subtropical regions to hydrological variations worldwide.

To explore this, we performed a teleconnection based time series analysis and analyzed its hydrological local impacts in the KP region, shown in Fig. 1. First, we analyzed stationary processes by the logarithmic transformation in each time series data set, such as ocean-related climate indices and hydrological data. Second, we analyzed the low frequency for the time series data sets by PCA using a SSA. Third, the joint probability distribution density function was derived from the SSA results using a kernel density method. The linear and non-linear lag time correlation of the joint probability distribution density function, derived using the MI technique, was used to analyze the atmospheric teleconnections. Finally, we assessed the impact of this teleconnection on hydro-meteorological variability and the resulting implications for local water resource management.

\subsection{Classification of ENSO events}

The emerging issue of the new type of El Niño phenomenon has caused significant changes in the hydro-meteorological patterns throughout the world. However, quantitative studies on features of CT/WP El Niño were found to be relatively in- 
sufficient for the Korean watersheds. The effect of different phases of ENSO on the summer precipitation and streamflow characteristics was analyzed by adopting the classification criteria proposed by Ren and Jin (2011) for hydrologic variables from the five major river basins in Korea and their 113 sub-basins. We calculated these variables and divided into the two different indices $\left(N_{\mathrm{CT}}\right.$ and $\left.N_{\mathrm{WP}}\right)$, which are indicated by the cold tongue and warm pool El Niño categorization proposed by Ren and Jin (2011) that used a simple nonlinear transformation to distinguish a CT El Niño from a WP El Niño. The equation is defined as follows:

$N_{\mathrm{CT}}=N_{3}-\alpha N_{4}$

$$
\alpha=\left\{\frac{2 / 5, N_{3} N_{4}}{0, \text { otherwise }} .\right.
$$

$N_{\mathrm{WP}}=N_{4}-\alpha N_{3}$

where, $N_{3}$ and $N_{4}$ mean indices of Niño3 and Niño4, respectively. $N_{\mathrm{CT}}$ and $N_{\mathrm{WP}}$ are new indices based on a simple transformation from Niño3 and Niño4 indices, and $\alpha$ indicate the correction constant.

\subsection{Principal component analysis using SSA}

Singular spectrum analysis (SSA) is a non-parametric spectral estimation method that reduces dispersion by changing the coordinates in time-series in derived techniques from principal component analysis (PCA), which enables the extraction of information from noisy time series. By removing the non-harmonic components from the original time series data, one can more easily understand its long-term frequency and trend (Moon and Lall, 1996). SSA embeds a time series data $X_{i}(1<i<N)$ in a vector space of dimension $M$ and applies the empirical orthogonal function (EOF) method.

To separate the non-harmonic components, the size of the eigenvalues is defined by the orthogonal process. The orthogonal function is calculated between $\alpha_{i}^{1}$ and $\alpha_{i}^{2}$, the orthogonal coefficients of the PC1 and PC2 time series, to correspond with the harmonic components in original coordinate $X$ and $Y$. Finally, it converted to the reconstruction component (RC) to $R_{i}^{1}$ and $R_{i}^{2}$. It is possible to configure the estimation forecasting model to reflect specific characteristics (such as frequency and trend) in original data. By reconstructing the data using Eq. (2), it is possible to replace the original data with a new time series, which has constant frequency and less noise.

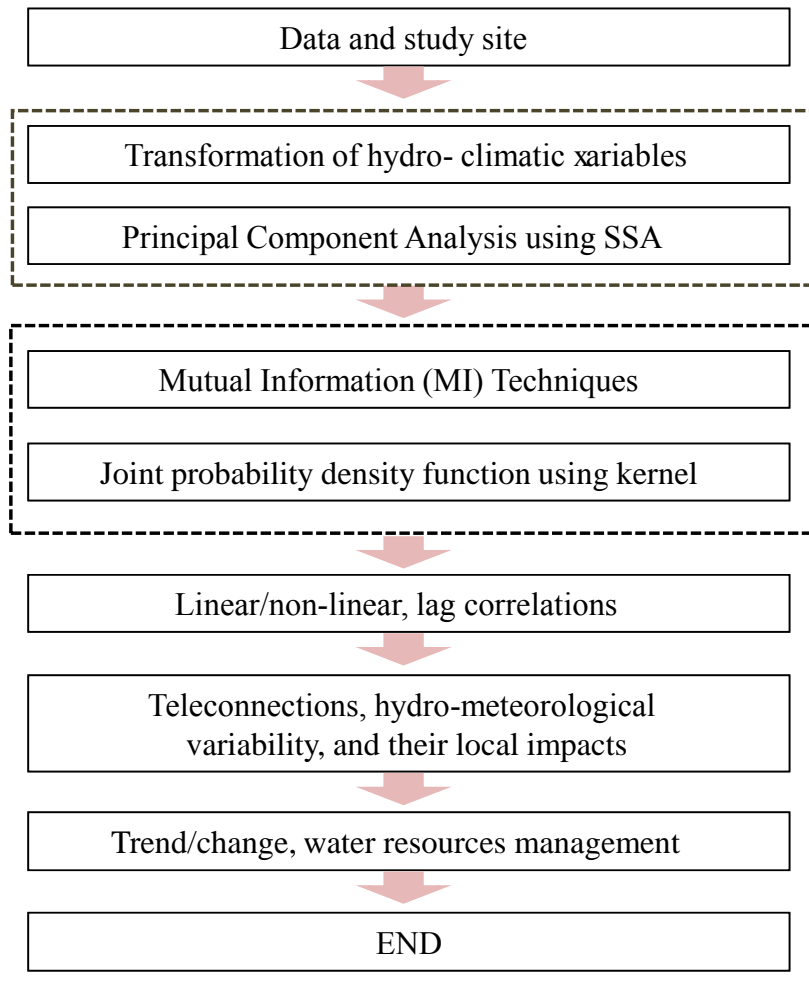

Figure 1. Flow chart of teleconnection based seasonal prediction study between climate indices and hydro-meteorological variables.

$\left(R_{A} X\right)_{i}=\frac{1}{i} \sum_{j=1}^{i} \sum_{k \in A}^{i} \alpha_{i-j}^{k} E_{j}^{k}, 1 \leq i \leq M-1$

$\left(R_{A} X\right)_{i}=\frac{1}{M} \sum_{j=1}^{M} \sum_{k \in A}^{i} \alpha_{i-j}^{k} E_{j}^{k}, M \leq i \leq N-M+1$

$\left(R_{A} X\right)_{i}=\frac{1}{N-i+1} \sum_{j=1-N+M}^{i} \sum_{k \in A}^{i} \alpha_{i-j}^{k} E_{j}^{k}$,

$N-M+2 \leq i \leq N$

Here, $\alpha_{i}^{k}$ means an orthogonal coefficient, $E_{j}^{k}$ is the empirical orthogonal function $(1 \leq k \leq M), M$ indicates a dimension, and $\tau$ is the sampling rate.

\subsection{Mutual information techniques}

Mutual information (MI) is a quantitative measurement of how much one random variable $(Y)$ tells us about another random variable $(X)$ and can also be thought of as the reduction in uncertainty about one random variable given knowledge of another. This is a useful tool for determining nonlinear correlation between the two different data sets. Here, we use it to extract information about the non-linear correlation between climate indices and hydrological variables in the KP. 
If we have two kinds of time series data sets such as $\left(s_{1}, s_{2}, s_{3}, \cdots, s_{n}, q_{1}, q_{2}, q_{3}, \cdots, q_{n}\right)$, where $n$ is the observed periods, then the MI value between observation $s_{i}$ and $q_{j}$ is defined by Moon et al. (1995) as follows:

$\mathrm{MI}_{\mathrm{s}, q}\left(s_{i}, q_{j}\right)=\log _{2}\left(\frac{P_{\mathrm{s}, q}\left(s_{i}, q_{j}\right)}{P_{\mathrm{S}}\left(s_{i}\right) P_{q}\left(q_{j}\right)}\right)$.

Here, $P_{\mathrm{s}, q}\left(s_{i}, q_{j}\right)$ indicates the joint probability density function between $s$ and $q$ calculated by a time series of $\left(s_{i}, q_{j}\right) . P_{\mathrm{s}}\left(s_{i}\right)$ and $P_{q}\left(q_{j}\right)$ are the marginal probability densities calculated from $s_{i}$ and $q_{j}$, respectively. The overall concern is the correlation between the two series of data. The average mutual information $\left(I_{\mathrm{s}, q}\right)$ of two discrete random variables s and $q$ can be defined as Eq. (4):

$I_{\mathrm{s}, q}=\sum_{i, j} P_{\mathrm{s}, q}\left(s_{i}, q_{j}\right) \log _{2}\left(\frac{P_{\mathrm{s}, q}\left(s_{i}, q_{j}\right)}{P_{\mathrm{s}}\left(s_{i}\right) P_{q}\left(q_{j}\right)}\right)$

where $P_{\mathrm{s}, q}\left(s_{i}, q_{j}\right)$ is the joint probability distribution function of $X$ and $Y$, and $P_{\mathrm{S}}\left(s_{i}\right)$ and $P_{q}\left(q_{j}\right)$ are the marginal probability distribution functions of $s$ and $q$, respectively. This equation is useful to search for the components in multivariate sampling whether independent and dependent.

In this study, we performed a linear regression (LR) approach with the estimated average MI value and a nonlinear regression using the method of Kernel density estimation (KDE). The $90 \%$ confidence bounds were estimated using 1000 bootstrap resampling replications, allowing for a more accurate calculation of the confidence bounds given the limited data.

\section{Analysis and results}

\subsection{Strong ENSO events and composite anomalies of SST}

A comparison of Niño3 and Niño4 anomalies using a scatter plot revealed a correlation of $0.77\left(R^{2}=0.593\right)$ between the two time series. However, a comparison between CT El Niño $\left(N_{\mathrm{CT}}\right)$ and WP El Niño $\left(N_{\mathrm{WP}}\right)$ indices yielded a correlation of only $0.19\left(R^{2}=0.034\right)$. Therefore, we confirmed the independence between $N_{\mathrm{CT}}$ and $N_{\mathrm{WP}}$ indices that showed a smaller relative correlation. To further examine local hydrologic responses within the context of seasonal variability, the six strongest events of CT El Niño years (1965/66, 1972/73, 1982/83, 1987/88, 1991/92, and 1997/98) were identified using the new $N_{\mathrm{CT}}$ index. The six strongest events of WP El Niño years (1968/69, 1990/91, 1994/95, 2002/03, 2004/05, and 2009/10) were identified using the Nwp index. The five strongest events of La Niña years (1973/74, 1975/76, 1988/89, 1999/00, and 2010/11) were selected using the classification criteria provided by the NOAA climate prediction center (CPC) during the SST observation period 1950-2013.
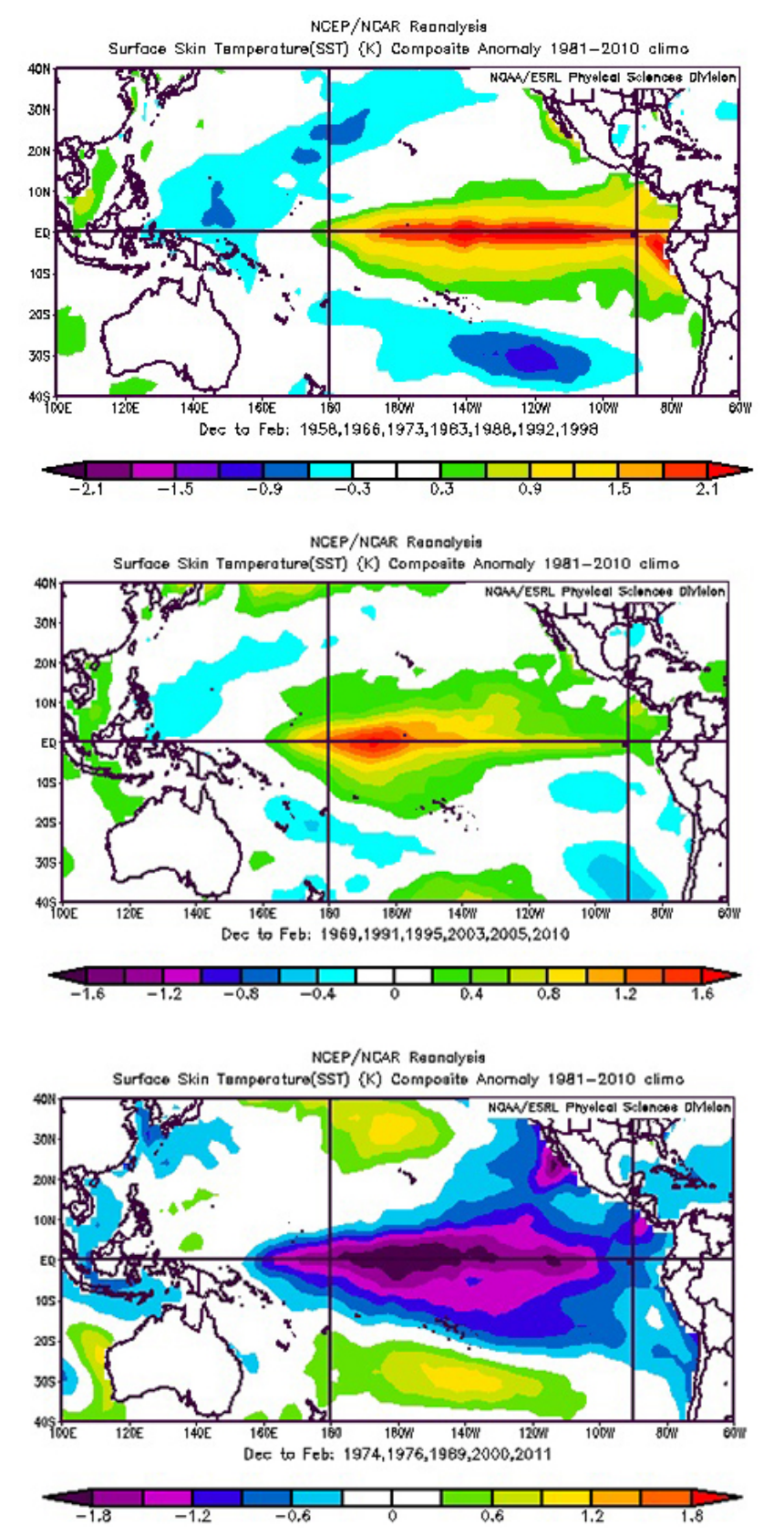

Figure 2. Composite sea surface temperature anomalies (SSTA) in the TPO region in developing phases of two types of El Niño and La Niña during December-January. (a) to (c) indicate SSTA during CT/WP El Niño and La Niña years, respectively.

Through this classification research, we confirmed that the WP type El Niño is occurring more frequently than the CT type El Niño in the Tropical Pacific Ocean in recent years. From the changes in frequency of WP to CT, we can see that using the subdivision proposed by Ren and Jin is necessary for more accurate analysis of the impacts of these major climatic events. 
Figure 2 shows the composite sea surface temperature anomalies of the mean SST in the TPO region in developing phases of two types of El Niño and La Niña during December-January. The SST data was obtained from the $\mathrm{Na}$ tional Centers for Environmental Prediction (NCEP) and the National Center for Atmospheric Research (NCAR) reanalysis version 2 and the 30-year climatology for the period of 1981-2010. In the case of CT El Niño years, the abovenormal anomalies occurred in the central Pacific and eastern Pacific regions while below-normal anomalies occurred throughout the western Pacific region (Fig. 2a). This warm anomaly grew stronger and extended to the west during the fall. In the winter, a positive SST anomaly pattern strengthened, but as spring arrived the CT El Niño weakened and disappeared. However, the case of WP El Niño pattern shows a slight yet clear difference when compared to the CT El Niño. In the WP El Niño years, above-normal SST anomalies clearly appeared in the central Pacific region and a slightly above-normal SST anomaly was observed in the eastern Pacific regions (Fig. 2b). This central Pacific warm anomaly grew stronger and extended to the east during the fall. In the wintertime, a positive SST anomaly pattern strengthened, but as spring arrived, the WP El Niño weakened and disappeared. In the case of La Niña years, a cold SST anomaly pattern was located in the eastern Pacific and central Pacific Ocean (Fig. 2c). This cold anomaly grew stronger and extended to the west during the fall. In the wintertime a negative SST anomaly pattern strengthened but, as spring arrived, the La Niña weakened and disappeared. Many recent studies (Kug et al., 2009; Feng et al., 2010) show these different SST anomaly patterns may affect air circulation and they are findings significant changes in different regions in seasonal precipitation over the Pacific region countries.

\subsection{Composite analysis for GPCC}

Figure 3 shows the composite anomalies (1981-2010 climatology) of Global Precipitation Climatology Center (GPCC) precipitation from June to September during strong ENSO events over the North East Asia domain. We extracted monthly precipitation for 1901-2013 from the GPCC full quality control data reanalysis version 6.0 at $0.5^{\circ} \times 0.5^{\circ} \mathrm{spa}-$ tial resolution from Deutscher Wetterdienst in Germany. The data set is the most accurate in situ precipitation reanalysis data set of GPCC (Schneider et al., 2011).

Data for two different CT/WP El Niño years, and La Niña years allowed for a characteristic analysis of GPCC rainfall over the Korean Peninsula. Figure 3a to c shows the regional scale variability of Korean summer (June-September) precipitation during CT/WP El Niño and La Niña years. During CT El Niño years (Fig. 3a), the GPCC precipitation shows anomalously dry conditions (10-50 mm lower than long-term normal) on the KP, while WP El Niño years show anomalously wet conditions (20-50 mm higher than long-term normal) (Fig. 3b). As well, La Niña years showed
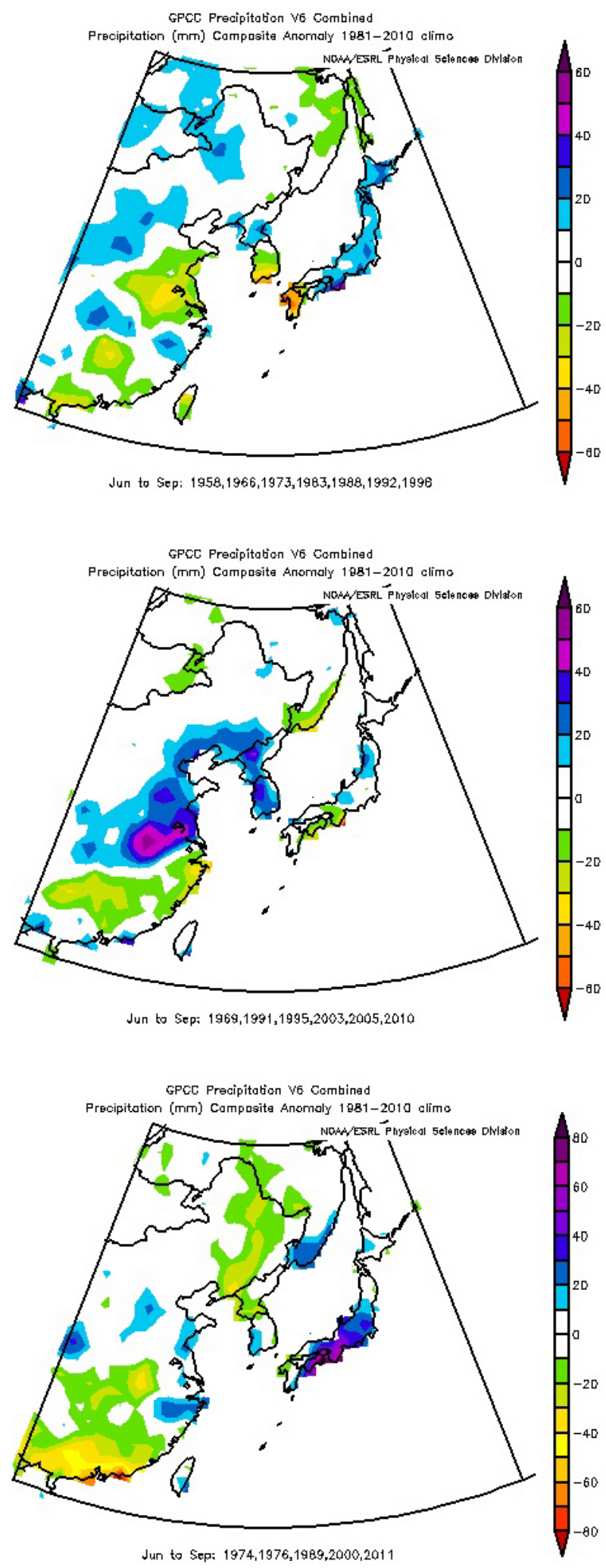

Figure 3. Composite anomalies (1981-2010 climatology) of GPCC Full V6 combined precipitation (JJAS: June to September) during ENSO events over the North East Asia domain. 


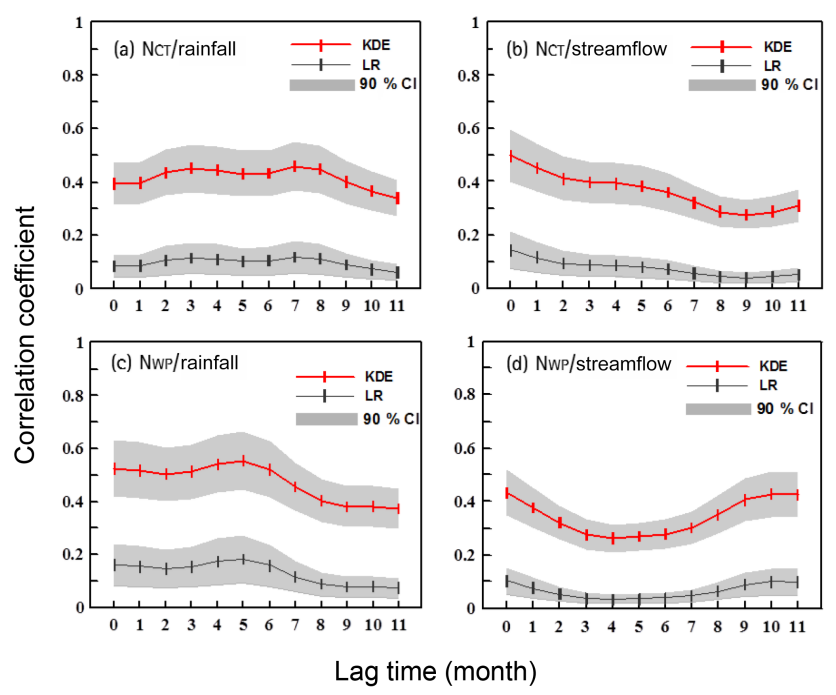

Figure 4. Nonlinear and linear CCs with their $90 \%$ confidence bounds between climate index and hydro-meteorological variable in the Korean Peninsula, using KDE and LR approaches, respectively. The confidence bounds are given by 5 and $95 \%$ quantiles of 1000 bootstrap replications.

slightly wet conditions: $0-10 \mathrm{~mm}$ higher than the long-term normal. While the results of this study rely on short observations and relatively limited data set, these findings are important to seasonal prediction for streamflow in basin scale and establishing adaptive solutions to changing climate related issues.

\subsection{Teleconnection results}

Figure 4 shows nonlinear and linear correlation coefficients (CCs) with their $90 \%$ confidence bounds between climate index and hydro-meteorological variable in the KP, using KDE and LR approaches respectively. As described in the methodology, we obtained the non-linear behaviors and their correlations between climate indices and hydro-meteorological variable from a MI analysis. The linear and non-linear correlation of the $N_{\mathrm{CT}}$ index and KP rainfall (LR: 0.118, KDE: 0.459) showed a 7-month lag time (Fig. 4a), while the correlation between the $N_{\mathrm{CT}}$ index and the KP streamflow (LR: 0.182, KDE: 0.553) showed direct influence (Fig. 4b). Moreover, an analysis of the correlation between the $N_{\mathrm{WP}}$ index with KP rainfall (LR: 0.118, KDE: 0.459) and streamflow (LR: 0.104, KDE: 0.433) showed a 5 and 10 months lag time respectively (Fig. 4c, d). These time-lags indicate the existence on a nonlinear correlation between climate indices and hydrological variables, potentially enabling the use of large scale climate indices in the seasonal prediction of water resources in KP.

\subsection{Seasonal variability during ENSO}

Figures 5 and 6 show composite anomalies of annual and JJAS (June to September) rainfall and river discharge during CT/WP El Niño and La Niña years in the basins of the KP. The hatched polygons indicate statistically significant changes in annual rainfall based on the $10 \%$ significance level by Student's $t$ test. As shown in Fig. 5, the annual rainfall anomalies reflect the sub-basin scale variability of Korean summer rainfall during CT/WP El Niño and La Niña events. Looking at the detailed variations in the subwatershed areas, we can capture the spatial and seasonal variability caused by ENSO.

During CT El Niño events (Fig. 5a, d), the annual/JJAS rainfall on the KP was $-7.06 \% /-11.18 \%$ lower than the long-term norm (1971-2000). The annual/JJAS streamflow during CT El Niño events (Fig. 6a, d) were decreased to $-10.04 \% /-18.28 \%$ in the basins of the KP. During WP El Niño events (Fig. 5b, e), the annual/JJAS rainfall on the KP increased to $10.94 \% / 20.09 \%$. The annual/JJAS streamflow during WP El Niño events (Fig. 6b, e) substantially increased to $15.58 \% / 24.52 \%$ in the basins of the KP. And during La Niña events (Fig. 5c, f), the annual/JJAS rainfall on the KP was $6.99 \% / 12.74 \%$ higher than long-term norm. The annual/JJAS streamflow during La Niña events (Fig. 6c, f) increased to $9.92 \% / 17.35 \%$ in the basins of the KP.

As a result of this composite analysis, a substantial increasing tendency of annual/JJAS rainfall and streamflow was found during WP El Niño events, while a significant decreasing trend was found during CT El Niño events, as compared to long-term normal years. In addition, the annual/JJAS rainfall and streamflow during La Niña event shows a slight tendency above normal.

Figure 7 shows a scatter plot of percentage change anomaly (departures from the 1971-2000 normal) changes between precipitation and streamflow during annual and JJAS season in different climate conditions of the ENSO events. ENSO conditions clearly show that the differences during the WP El Niño year $(+17.93 \%,+26.99 \%)$, the CT El Niño year $(-8.20 \%,-15.73 \%)$, and the La Niña year $(+8.89 \%,+15.85 \%)$, respectively.

Throughout the results, different phase of ENSO events clearly show influence on hydrologic seasonal variability in the KP and its sub-watersheds. This shows a linkage of possible teleconnections and characteristic changes between major climactic events and hydrological indicators.

\section{Summary and conclusions}

The mechanism of major climate phenomena such as El Niño and La Niña has not yet been fully understood. It is currently impossible to completely simulate these large-scale climate phenomena using the physical climate model, which would require perfect knowledge of the global environment and its weather conditions. Furthermore, analyzing climatic 
(a) CT El Nino

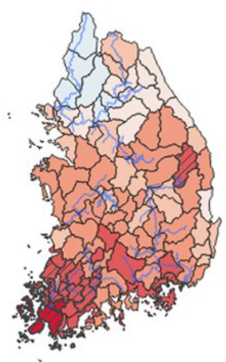

8

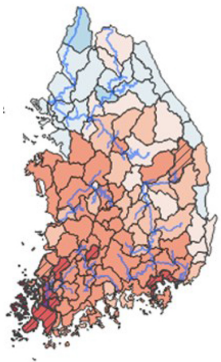

Q (b) WP El Nino

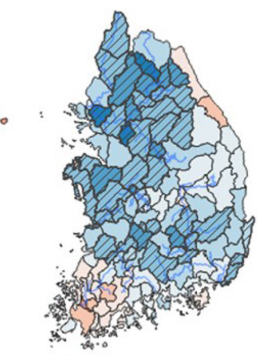

8

(e) WP El Nino

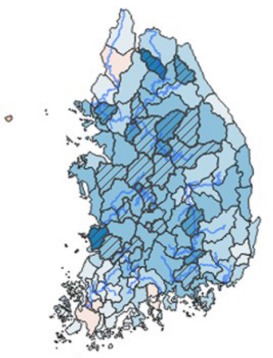

8 (c) La Nina

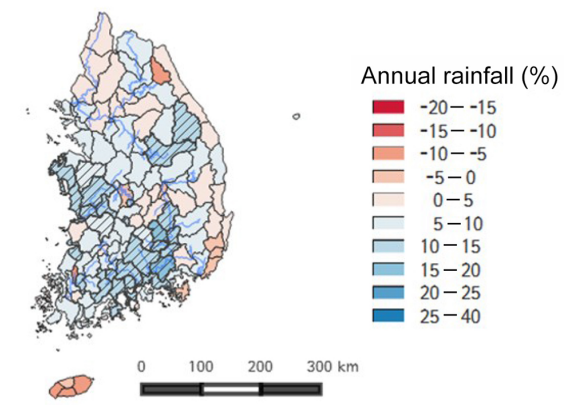

(f) La Nina

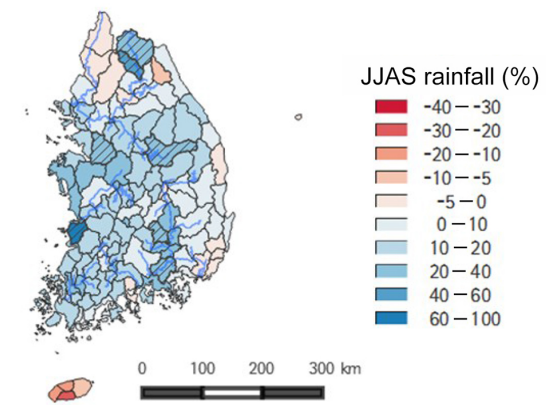

Figure 5. Composite anomalies of annual and JJAS (June to September) rainfall during CT/WP El Niño and La Niña years. The hatched polygons indicate statistically significant changes in annual rainfall based on the $10 \%$ significance level.

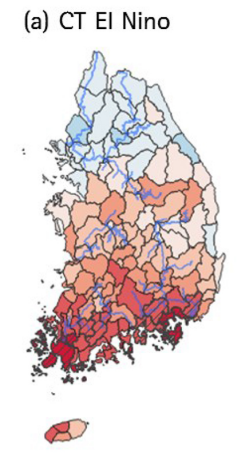

(d) CT El Nino

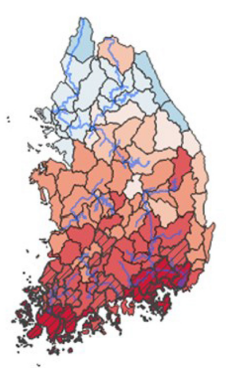

Q (b) WP El Nino

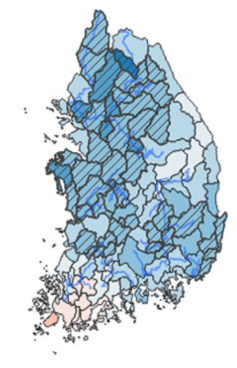

(2) (c) La Nina

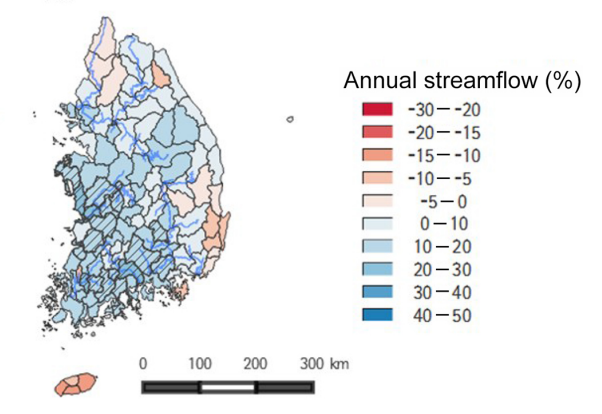

(f) La Nina

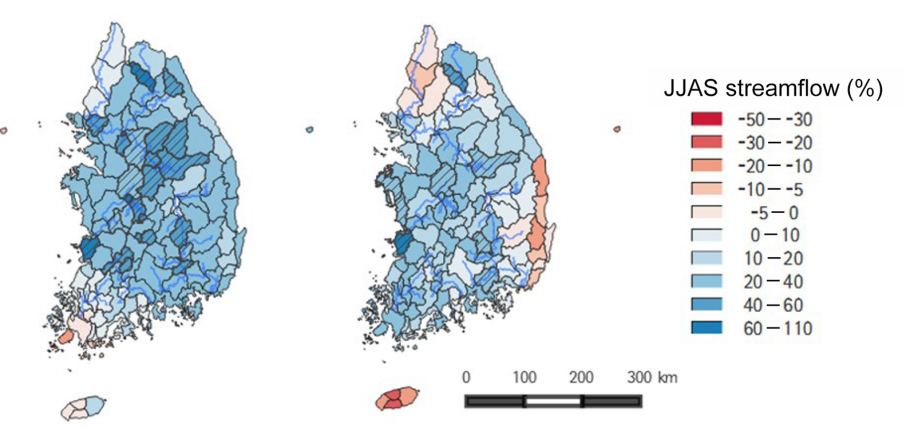

Figure 6. Same as Fig. 5, but for streamflow. 


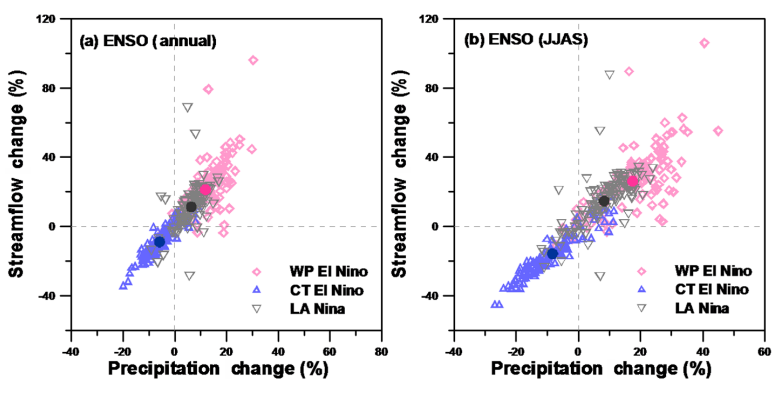

Figure 7. Scatter plot of percentage change anomaly (departures from the 1971-2000 normal) changes between precipitation and streamflow in different climate conditions. (a) and (b) show during annual and JJAS season in strong ENSO events in the 113 subwatershed in KP.

phenomena through the physical model is only possible in limited geographical areas, as predicting involves considerable difficulties. With these considerations, this study analyzed non-linear behavior links of the atmospheric teleconnections between hydrologic variable and climate indices using statistical models. One disadvantage of the statistical approach is that the limited number of observation reduces the significance level of the results. This is why the statistical model is utilized to complement to the prediction result of the physical model, resulting in more significant results.

Results from composite analysis in JJAS seasonal rainfall and river discharge during the CT/WP El Niño and the La Niña events in the KP and its sub-watershed show that the WP El Niño years show a substantially increasing tendency than normal years. The CT El Niño decaying years show a significantly decreasing tendency compared to the normal years. In addition, the La Niña years shows a slightly increasing tendency and normal condition. Also the MI based nonlinear and linear teleconnections using KDE and LR between climate indices and hydrologic variables show that the nonlinear CCs were higher than linear correlations, and the ENSO has a few months lag time correlation on rainfall and streamflow anomalies over the KP region.

This result shows a methodology of the teleconnection based long-range water resources seasonal prediction for reducing a changing climate uncertainty, when abnormal SSTA (such as, El Niño, La Niña) phenomenon occurs in the TPO regions. Furthermore, these results are useful water managers and end-users to support long-range water resources prediction and water-related policy making. A better understanding on hydrologic natural and anthropogenic drivers of this relationship between ENSO and streamflow could help to scientists to prepare river discharge control in the major river basins in KP. In addition, this research will facilitate wellinformed decision-making in minimizing climate-related disasters such as flood and drought on agriculture sector, and supports optimal development of strategies ensuring use of water resources in best management under a changing climate.

\section{Data availability}

The data set of precipitation and streamflow over Korean Peninsula are respectively available at the Korean government's Water Resources Management Information System (WAMIS), http: //www.wamis.go.kr/eng/WKW_ABGRF_LST.aspx and http://www.wamis.go.kr/eng/WKW_CMS_LST.aspx. Sea surface temperature data set from the National Oceanic and Atmospheric Administration (NOAA) is accessible at the Earth System Research Laboratory (ESRL), http://www.esrl.noaa.gov/psd/data/gridded/tables/sst.html.

The composite Global Precipitation Climatology Center (GPCC) Precipitation V6 Combined data is accessible at the Physical Sciences Division at NOAA's ESRL, http://www. esrl.noaa.gov/psd/cgi-bin/data/composites/printpage.pl/.

Acknowledgements. This research was supported by the APEC Climate Center and we appreciate the reviewers for their valuable comments of this article.

\section{References}

Ashok, K. and Yamagata, T.: Climate change: The El Niño with a difference, Nature, 461, 481-484, doi:10.1038/461481a, 2009.

Dressler, K. A., Leavesley, G. H., Bales, R. C., and Fassnacht, S. R.: Evaluation of girdded snow water equivalent and satellite snow cover products for mountain basins in a hydrologic model, Hydrol. Process., 20, 673-688, 2006.

Feng, J., Chen, W., Tam, C. Y., and Zhou, W.: Different impacts of El Niño and El Niño Modoki on China rainfall in the decaying phases, Int. J. Climatol., 31, 2091-2101, doi:10.1002/joc.2217, 2010.

GPCC (Global Precipitation Climatology Center): http://www.esrl. noaa.gov/psd/cgi-bin/data/composites/printpage.pl, last access: November 2014.

IPCC (Intergovernmental Panel on Climate Change): Managing the Risks of Extreme Events and Disasters to Advance Climate Change Adaptation (SREX) - Special Report of the Intergovernmental Panel on Climate Change, Cambridge University Press, 1-594, 2007.

Kim, J. S., Jain, S., and Yoon, S. K.: Warm season streamflow variability in the Korean Han River Basin: Links with atmospheric teleconnections, Int. J. Climatol., 32, 635-640, doi:10.1002/joc.2290, 2012.

Klein, S. A., Soden, B. J., and Lau, N. C.: Remote sea surface temperature variations during ENSO: Evidence for a tropical atmospheric bridge, J. Climate, 12, 917-932, 1999.

Kug, J. S., Jin, F.-F., and An, S.-I.: Two types of El Niño events: Cold tongue El Niño and warm pool El Niño, J. Climate, 22, 1499-1515, doi:10.1175/2008JCLI2624.1, 2009. 
Leavesley, G. H., Lichty, R. W., Troutman, B. M., and Saindon, L. G.: Precipitation-Runoff Modeling System: User's Manual, Water Resources Investigations: 83-4238, U.S. Geological Survey, Denver, Colorado, 1983.

McPhaden, M. J., Zebiak, S. E., and Glantz, M. H.: ENSO as an integrating concept in Earth Science, Science, 314, 1740-1745, 2006.

Moon, Y. I. and Lall, U.: Atmospheric flow indices and interannual Great Salt Lake variability, J. Hydrol. Eng., 1, 55-61, 1996.

Moon, Y., Rajagopalan, B., and Lall, U.: Estimation of mutual information using kernel density estimators, Phys. Rev. E, 52, 23182321, 1995.

NOAA (National Oceanic and Atmospheric Administration), National Weather Service Climate Prediction Center, 2014: http: //www.cpc.ncep.noaa.gov/data/indices/, last access: November 2014.

Piechota, T. C. and Dracup, J. A.: Drought and regional hydrologic variation in the United States: Associations with the El NiñoSouthern Oscillation, Water Resour. Res., 32, 1359-1373, 1996.

Piechota, T. C., Chiew Francis, H. S., Dracup, J. A., and McMachon, T. A.: Seasonal streamflow forecasting in eastern Australia and the El Niño-Southern Oscillation, Water Resour. Res., 34, 3035-3044, 1998.

Pizarro, G. and Lall, U.: El Niño-induced flooding in the U.S. West: What can we expect?, Eos Trans. Amer. Geophys. Union, 83, 349-352, 2002

Rayner, N. A., Parker, D. E., Horton, E. B., Folland, C. K., Alexander, L. V., and Rowell, D. P.: Global analyses of sea surface temperature, sea ice, and night marine air temperature since the late nineteenth century, J. Geophys. Res., 108, doi:10.1029/2002JD002670, 2003.
Ren, H. L. and Jin, F. F.: Niño indices for two types of ENSO, Geophys. Res. Lett., 38, L04704, doi:10.1029/2010GL046031, 2011.

Schneider, U., Becker, A., Finger, P., Meyer-Christoffer, A., Rudolf, B., and Ziese, M.: GPCC Full Data Reanalysis Version 6.0 at $0.5^{\circ}$ : Monthly Land-Surface Precipitation from Rain-Gauge built on GTS-based and Historic Data, doi:10.5676/DWD_GPCC/FD_M_V6_050, 2011.

Trenberth, K. E.: The definition of El Niño, B. Am. Meteorol. Soc., 78, 2771-2777, 1997.

WAMIS (Water Management Information System): http://wamis. go.kr/eng/, last access: September 2015.

Wang, B., Wu, R., and Fu, X.: Pacific-East Asia Teleconnection: How Does ENSO Affect East Asian Climate?, J. Climate, 13, 1517-1536, 2000.

Yeh, S. W., Kug, J. S., Dewitte, B., Kwon, M. H., Kirtman, B. P., and Jin, F.-F.: El Niño in a changing climate, Nature, 461, 511-514, doi:10.1038/nature08316, 2009.

Yoon, S. K.: Extreme climate patterns and their hydrologic impacts over the Korean Peninsula: Links with atmospheric teleconnections, APEC Climate Center Research Report, 2015-12, 1-181, 2015.

Yoon, S. K., Kim, J. S., Lee, J. H., and Moon, Y. I.: Hydrometeorological variability in the Korean Han River Basin and its subwatersheds during different El Niño phases, Stoch. Environ. Res. Risk Assess., 27, 1465-1477, 2013. 